\title{
Design, Fabrication and Testing of a Platform with Steam Heat Exchangers for Drying of Parboiled Paddy Rice and Other Agricultural Products
}

\author{
Agidi Gbaboํ, Andrew N. Efomah², and Gana Ibrahim Mohammed ${ }^{3}$ \\ ${ }^{1}$ Department of Agricultural and Bioresources Engineering, Federal University of Technology, PMB 65, Minna, \\ Niger State, Nigeria \\ ${ }^{2}$ Department of Agricultural and Biosystems Engineering, University of Ilorin, Ilorin, Kwara State, Nigeria \\ ${ }^{3}$ Department of Agricultural and Bioenvironmental Engineering, Federal Polytechnic Bida, Niger State, Nigeria \\ Email: ganaibro74@yahoo.com
}

\begin{abstract}
A steam heated platform dryer with a capacity of 4 tons per day was designed and fabricated in Desfabeng Company Nigeria limited, Bida, Niger State, Nigeria. The system is made up of the following components; a boiler, pressure relief valve, drain valve, drying bed, furnace and heat exchangers pipes. Evaluation of the system was carried by comparing its performance with the direct sundry method. The results of the testing revealed that the steam heated platform dryer showed a uniform drying rate and a limited drying time of two hours for $335 \mathrm{~kg}$ of parboiled paddy with a head rice recovery of $90 \%$ and a moisture removal rate of $16 \mathrm{~kg} / \mathrm{hr}$. While for the sundried method a moisture content of $22 \%(\mathrm{wb})$, moisture removal rate of $8 \mathrm{~kg} / \mathrm{hr}$ and head rice recovery of $50 \%$ was obtained. The dryer was found to be very easy to operate and maintain due to its simple design.
\end{abstract}

Keywords: Design, dryer, fabricate, steam, platform

\section{Introduction}

Rice is one of the most important food crops as $80 \%$ of people around the world consume rice. Paddy rice production stands at more than 730 million tons or 487 million tons of milled rice and Asian farmers produce about $90 \%$ of this total [1]. The moisture content of paddy at harvest can be as high as $28-35 \%$ wet basis (wb), especially when harvested during the rainy season. Paddy rice should be dried to typically $12-15 \%$ (wb) moisture content, which is known to be adequate for safe milling, handling and whitening and then stored as milled dried in order to prevent the production of mycotoxins [2].

Drying is the removal of moisture from a porous medium by evaporation. Drying of Agricultural products such as paddy rice, melon, millets, sorghum, yam chips etc. helps in reducing the moisture content to a lower moisture content safe for storage. Moisture removal from agricultural product depends on their drying temperature, velocity, relative air humidity, variety and maturity. Hence, various isolated and combined parameters are involved in moisture removal from grains (Couto, 2002). Drying of rice is a non-linear process with long time delay and considerable complexity. Therefore, it is very difficult to establish a precise mathematical model for grain drying control [3].

A cyclone type thin-layer dryer for drying Agricultural materials was developed by [4]. This system was used for drying study of vegetables and fruits including potato, red pepper, apple, strawberry, pumpkin and eggplant slices. Different drying operations result in extensive kernel fissuring with significant broken ratio during subsequent husking and milling. Excessive air drying often results in over-dried grains, which become brittle and predisposed to cracking.

According to [5] there are two methods of drying rice namely; sun drying and mechanical drying. The sun drying of parboiled paddy involves spreading of the material to a thickness of 2-3cm on a drying floor with a wooden board to utilize the sun's energy. This method of drying is widely practiced in conventional rice mills and by small scale farmers. The shortcomings of this method for drying paddy rice are numerous which include: it takes a longer period of time to dry grains to the desire moisture content. This exposed the grains to atmospheric factors, pest attack (insects, rodents, birds) and microorganisms (moulds). Also to have uniform drying, the grain must be stirred frequently at least once per 
hour, better every 30 minutes. This is tedious and time taking. In addition for drying to be effective, the relative humidity of the ambient air must not be higher than 70 percent. This means the grain must not be exposed at night due to the cold of the night that fosters rehumidification of grain. Thus, this method of drying is not suitable in humid regions or during the rainy season. On hot days the grain temperature can rise above the recommended seed drying temperature of not higher than $43^{\circ} \mathrm{C}$ to over $50-60^{\circ} \mathrm{C}$. This can cause excessive grain breakage during milling operation [2]. On the other hand the mechanical drying entails forcing hot air through the parboiled paddy to evaporate and remove the moisture. Continuous flow and rotary dryers were in use in modern rice processing factories. Mechanical drying has the advantage that suitable drying air conditions can be set and that drying can be carried out anytime of the day or night. The use of mechanical drying may also reduce the labour costs especially if some form of mechanical turning or stirring of grain is practiced, as in the case of recirculating dryers.

The advantages of mechanical drying cannot be overemphasized, although most of the mechanical dryers like the rotary and continuous flow dryers are too sophisticated requiring high level of expertise. This is a major hindrance to local processors as most of them are not learned. Hence, the development of a steam heated platform dryer becomes necessary in order to overcome the shortcomings of the existing methods. The new technology can easily be used and maintained by local processors. It can be fabricated using locally sourced material and the design would be easily replicated by local fabricators. Thus, this paper is the presentation of development and testing of a steam heated platform dryer which would be found very useful in drying agricultural products thereby eliminating the problems encountered during sun drying.

\section{$2 \quad$ Materials and Methods}

The materials used and methods followed were as follows.

\subsection{Sample Preparation}

A $700 \mathrm{~kg}$ of Faro 35 paddy rice was obtained from the National Cereal Research Institute (NCRI) Badeggi, Bida, Nigeria. The collected paddy rice sample was thoroughly cleaned from dirts and premature grains in a wet cleaner and afterwards parboiled [6]. The initial moisture content of the paddy was measured using digital moisture meter (TK 100S) with accuracy of 0.05 [7].

\subsection{Materials Selection}

A mild steel material was used for construction of the boiler, while concrete blocks were used for construction of the drying bed. $6 \mathrm{~cm}$ galvanized pipes were used as inter connecting pipes [8].

\subsection{Description of the Machine}

The steam heated platform dryer consists of the following;

i. Boiler: the boiler as shown in Figure 3 is cylindrical in shape with a diameter and length of 150 and $166 \mathrm{~cm}$ respectively. It was raised $80 \mathrm{~cm}$ above ground level. The boiler was fabricated with gauge 16 mild steel sheets. Attached to the top of the boiler is a pressure relief valve to relieve the boiler of excess pressure. Also attached to the top of the boiler is water inlet port for inflow of water and at the base a drain valve was attached for draining of water out of the boiler.

ii. The Drying Bed: this is a cabin box-rectangular shaped platform with dimensions of 304 by 304 by $30 \mathrm{~cm}$ as shown in Figures 2 and 3 . It was raised $40 \mathrm{~cm}$ above the ground level with its center concrete in order to minimize heat loss by conduction. A draining valve comprising of perforated pipes with a diameter of $6 \mathrm{~cm}$ and length $304 \mathrm{~cm}$ was fixed at side of the drying bed. Hollow pipes with diameter $5 \mathrm{~cm}$ were incorporated within the concrete thus serve as route for the steam passage. The drying surface is surrounded with a wood of $5 \mathrm{~cm}$ height in order to prevent the grain from falling/pouring out during the stirring operation.

iii. Interconnecting Pipes: galvanized pipes of $6 \mathrm{~cm}$ diameter were used to connect the boiler and the platform dryer through a $6 \mathrm{~cm}$ diameter gate valve and union connector as shown in Figure 2 . 


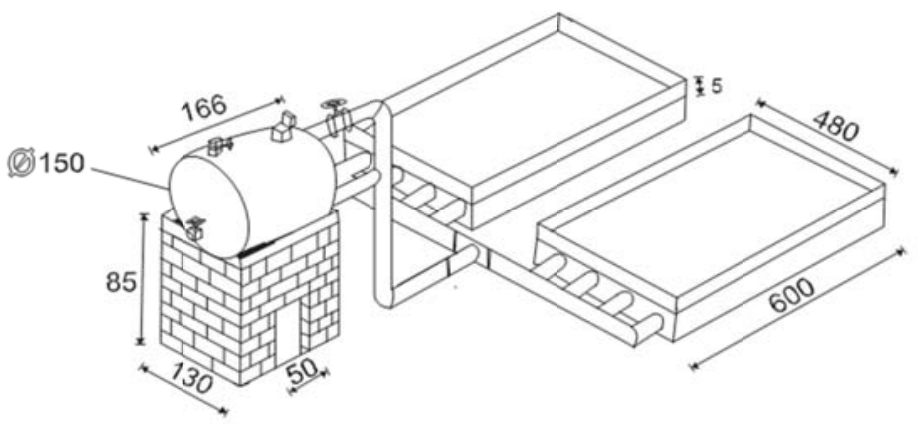

Figure 1. Isometric view of the developed platform with steam heat exchangers for drying of parboiled paddy rice and other agricultural products (All dimensions are in $\mathrm{mm}$ )

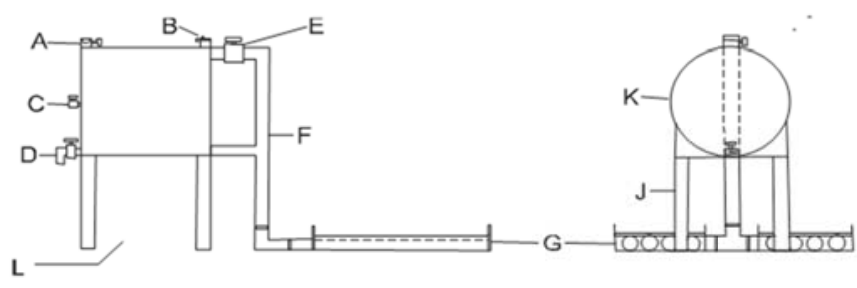

A

B

Figure 2. A-Orthographic side view, B-Orthographic back view of the developed platform with steam heat exchangers for drying of parboiled paddy rice and other agricultural products

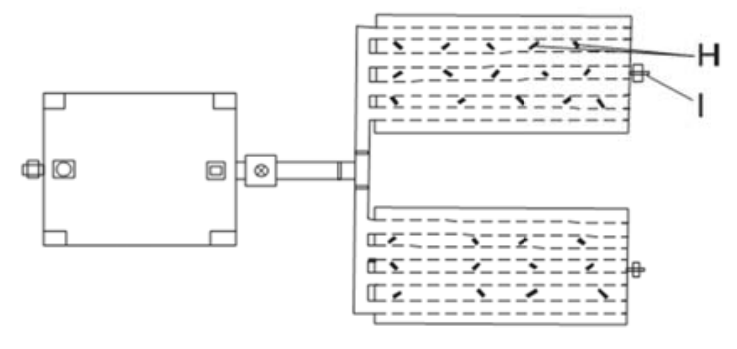

\begin{tabular}{|l|l|}
\hline KEYS & \multicolumn{1}{|c|}{ NOTATIONS } \\
\hline A & WATER INLET PORT \\
B & PRESSURE RELIEF VALVE \\
C & WATER LEVEL CONTROL VALVE \\
D & DRAINAGE VALVE \\
E & STEAM REGULATORY VALVE \\
F & STLAM PIPC \\
G & FLAT BED DRYER \\
H & STEAM DIRECTION OBSTACLES \\
I & CONOENSED STE $M$ M OUTLET \\
$J$ & FRAMEISUPPORT \\
K & BOILERTANK \\
L & SPACE FOR BRICK FIRE FURNACE \\
\hline
\end{tabular}

Figure 3. Orthographic plan view of the developed platform with steam heat exchangers for drying of parboiled paddy rice and other agricultural products

\subsection{Design Calculation}

The volume of the boiler is the sum of the volume of water required for steam formation and the excess volume of boiler required for steam generation is assumed to be $50 \%$ of actual volume of water for boiling, which is expressed as:

$$
\begin{gathered}
V_{B}=V_{W}+50 \% V_{W} \\
V_{B}=\frac{M_{W}}{\rho_{W}}+50 \% \frac{M_{W}}{\rho_{W}}
\end{gathered}
$$

where, $\mathbf{V}_{\mathrm{B}}=$ Volume of boiler $\left(\mathbf{m}^{3}\right), \mathbf{V}_{\mathrm{w}}=$ Volume of water $\left(\mathbf{m}^{3}\right)$, 
$M_{\mathrm{w}}=$ Mass of water required for steam formation $(\mathrm{kg}), \rho_{\mathrm{w}}=$ Density of water $\left(\mathrm{kg} / \mathbf{m}^{3}\right)$, $50 \%$ of $\mathrm{VW}$ is the assumed excess volume of boiler required for steam generation.

\subsubsection{Height of Boiler}

The height of the boiler was obtained as reported by [6]

$$
\begin{aligned}
\mathbf{H} & =\frac{\mathbf{V}_{\mathrm{B}}}{\mathbf{A}_{\mathrm{B}}} \\
\mathbf{A}_{\mathrm{B}} & =2 \pi \mathrm{r}_{\mathrm{B}}^{2}
\end{aligned}
$$

where, $\mathbf{H}=$ Height of boiler $(\mathbf{m}), \mathbf{V}_{\mathrm{B}}=$ Volume of boiler $\left(\mathrm{m}^{3}\right), \mathbf{A}_{\mathrm{B}}=$ Area of the boiler $\left(\mathbf{m}^{2}\right)$, $r_{B}=$ radius of the circular surface of boiler $(m)$

\subsubsection{Volume of Dryer}

The volume of the dryer is the sum of the volume of paddy the dryer can accommodate and the excess volume allowed for the free stirring of the paddy without the paddy pouring over. This excess volume is assumed to be twice of the paddy volume.

$$
\begin{gathered}
V_{D}=V_{R}+2 V_{R} \\
V_{D}=\frac{M_{R}}{\rho_{R}}+2 \frac{M_{R}}{\rho_{R}}
\end{gathered}
$$

where, $V_{D}=$ Volume of dryer $\left(\mathbf{m}^{3}\right), V_{R}=$ Volume of Paddy rice $\left(\mathbf{m}^{3}\right)$, $M_{R}=$ Mass of paddy rice to be $\operatorname{dried}(\mathrm{kg}), \rho_{\mathrm{R}}=\operatorname{Density}$ of $\operatorname{Paddy} \operatorname{rice}\left(\mathrm{kg} / \mathrm{m}^{3}\right)$.

\subsubsection{Height of Dryer}

$$
\mathbf{H}_{\mathrm{D}}=\mathbf{H}_{\mathrm{C}}+\mathbf{H}_{\mathrm{W}}
$$

where $\mathbf{H}_{\mathrm{D}}=$ Height of dryer $(\mathbf{m}), \quad \mathbf{H}_{\mathrm{C}}=$ Height of rectangular cabin - box encasement $(\mathbf{m})$, $\mathrm{H}_{\mathrm{W}}=$ Height of raised wooden incorporated metallic fold that guides the paddy $(\mathrm{m})$.

2.4.4 Heat Loss through the Walls of the Dryer

Heat loss through the walls of the dryer was expected, hence it was considered in the design. Considering the dryer as a flat surface, Fourier's law of heat conduction was applied as given below;

$$
q=\frac{K A \Delta T}{x}
$$

where, $q=$ Heat loss $(W), A=$ Heat transfer Area $\left(\mathrm{m}^{2}\right), \quad \mathrm{x}=\operatorname{Material}$ thickness $(\mathrm{m})$,

$\mathrm{K}=$ Thermal conductivity of the material $(\mathrm{W} / \mathrm{m} . \mathrm{K})$,

$\mathrm{T}=$ Temperature difference across the material $(\mathrm{k})$,

\subsubsection{Amount of Moisture to be Removed}

The amount of moisture expected to be removed was computed as the difference between the mass of parboiled paddy before drying and the mass of the dried paddy after drying. It is expressed as;

$$
M_{R}=M_{W}-M_{D}
$$

where, $M_{R}=$ Mass of moisture memoved $(\mathrm{kg}), M_{W}=$ Mass of parboiled paddy before $\operatorname{drying}(\mathrm{kg})$, $\mathrm{M}_{\mathrm{D}}=$ Mass of dried paddy $(\mathrm{kg})$.

\subsection{Mode of Operation and Testing of the Machine}

The boiler was filled with water to half of its height so as to leave a vacuum at the upper part of the boiler for sufficient steam generation. Heat was then supplied to the boiler through firewood placed at its bottom and surrounded by a low walled brick furnace. The heat generated by the firewood was used to raise the temperature of the water in the boiler until the water begins to boil vigorously in order for sufficient steam to be formed. The generated steam was then channeled through interconnecting pipes to the platform dryer [9]. The already parboiled paddy was divided into two equal parts of $335 \mathrm{~kg}$ each. 
One part was spread under the sun for drying to take place by the heat of the sun and natural air movement across the evenly spread paddy rice. The second part $(335 \mathrm{~kg})$ of the parboiled paddy was then evenly spread on the drying surface of the steam heated platform dryer. Prior to the pouring of the parboiled paddy on the drying surface, the platform was steam heated by passing the already generated steam from the boiler via the connecting pipe to the platform dryer through the action of the gate valves. The parboiled paddy on the drying platform and under the sun was continuously stirred with a specially constructed rake so as to mix the paddy and ensure even drying. The decrease in moisture content for both sun drying and steam heated platform drying was taken and recorded at an interval of twenty minutes. After about two hours of continuous stirring, it was observed that the initial moisture content of the parboiled paddy has reduced for both the sundried and platform dried paddy. The dried paddy was allowed to cool, so that the fissured cracks that were formed during the parboiling process can properly close up so as to obtain a full strong grain without cracks with a view of avoiding broken grains during milling operation. After the tempering process, milling was carried out and the head rice recovery was calculated for both drying processes as (Adesoji and Abiola, 2014):

$$
H_{R}=\frac{M_{H}}{M_{R}}
$$

where, $M_{H}=$ Mass of head rice, $M_{R}=$ Total mass of milled rice, Head rice = milled rice with length greater or equal to three quarters of the average length of the whole kernel.

So, the rate of moisture removal was evaluated as:

$$
\mathrm{R}_{\mathrm{M}}=\frac{\mathrm{M}_{\mathrm{A}}}{\mathrm{T}_{\mathrm{R}}}
$$

where $\mathrm{R}_{\mathrm{M}}=$ Rate of moisture removal $(\mathrm{kg} / \mathrm{h}), \mathrm{H}_{\mathrm{R}}=$ Head rice recovery,

$\mathrm{M}_{\mathrm{A}}=$ Amount of moisture removed $(\mathrm{kg}), \mathrm{T}=$ Time taken for the drying process $(\mathrm{h})$.

\subsubsection{Determination of the Capacity of the Dryer}

The capacity of the dryer is equivalent to the mass of paddy rice that the dryer can accommodate for the purpose of drying at a specified duration of time.

$$
\begin{gathered}
\text { Volume }=\text { Area } \times \text { Height } \\
\text { Area }=\mathrm{L} \times \mathrm{B}
\end{gathered}
$$

where, $\mathrm{L}=$ Length of the dryer $(\mathrm{m}), \mathrm{B}=$ Breadth of the dryer $(\mathrm{m})$.

The drying time is dependent on the strength of the steam entering the platform dryer from the steam generation chamber. Test results revealed an average drying time of two hours for $335 \mathrm{~kg}$ of paddy rice. This was obtained by continuous stirring of the paddy on the platform accompanied by regular checking of the moisture content of the paddy with a digital moisture meter at intervals of twenty minutes to obtain a moisture content of $14 \% \mathrm{wb}$. At a drying time of $2 \mathrm{hrs}$, the moisture content has reduced to $14 \% \mathrm{wb}$. This indicates that the dryer can dry paddy rice from initial moisture of $30 \% \mathrm{wb}$ to a final moisture content of $14 \% \mathrm{wb}$ within $2 \mathrm{hrs}$. As such in $24 \mathrm{hrs} /$ one day,

$$
\frac{335 \mathrm{~kg} \times 24 \mathrm{hrs}}{2 \mathrm{hrs}}=4,020 \mathrm{~kg}
$$

Therefore, 4,020 $\mathrm{kg}$ of paddy rice would be dried.

\section{$3 \quad$ Result and Discussions}

The result of the test carried out on the steam heated platform dryer in comparison to the sun drying method is presented in Figure 4.

\subsection{Effects of Drying Methods and Drying Time of the Paddy on Moisture Removal}

The initial moisture content of the two paddy samples was $30 \%$ (wb) each. After 20 minutes of drying no significant changes were observed in the moisture content of the samples. This could be similar to the case at the initial time, both hot steam passes from the platform and hot air from the sun causes 
moisture on the outside of the kernels to evaporate into the air. During that period the initial moisture removal was at the surface of the sample. The rate is almost equal regardless of the method applied.

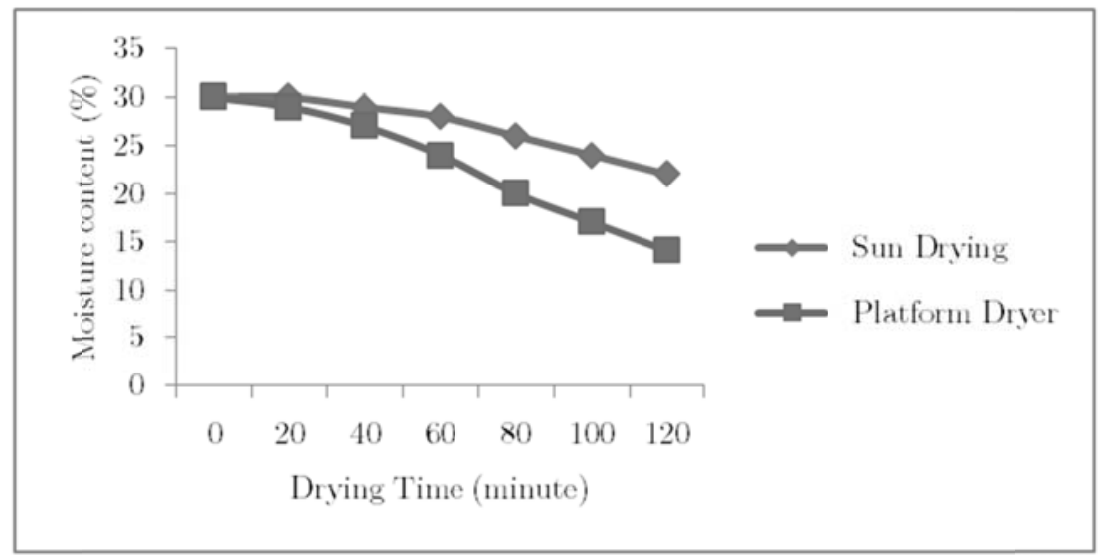

Figure 4. Relationship between moisture content and drying time of the paddy rice dried using platform and sun drying methods

Different drying methods for paddy rice were reported by [10]. The author indicated that during drying process moisture is first removed from surface of the material. From drying time of 40 minutes to 120 minutes significant differences were observed between the two methods. The platform was observed to remove more moisture than the sun drying method. This could be as result of faster migration of moisture trapped inside the kernel to the kernel surface where it was absorbed by the warm air. Thus, a chain reaction takes place - warm air evaporates surface moisture which in turn causes moisture from the inside of the kernel to travel to the surface. The hot steam not only holds much more moisture, but increases the vapor pressure of the moisture in the kernel and drives the moisture out from the interior of the kernel. Thus, the higher the surface temperature which can be achieved without damage to the interior of the kernel, the more quickly the internal moisture will migrate to the surface for evaporation. The kernel will dry more quickly, therefore allowing greater capacity in the drying system. The platform dryer proves to be very effective as it was able to dry paddy from an initial moisture content of $30 \%$ wb to a final moisture content of $14 \%$ within a time frame of two hours for $335 \mathrm{~kg}$ of paddy.

\subsection{Rice Recovery}

The result on rice recovery values showed that the rice dried using the platform and milled with moisture content of $14 \%$ had high recovery of $90 \%$ while the sample dried using sun drying method and milled with moisture content of $22 \%$ had low recovery value of $50 \%$. The drying method and paddy rice moisture content have significantly influenced $(\mathrm{P}<0.05)$ on rice recovery. Samples dried using sun drying methods had high moisture content; this makes the rice kernel soft to withstand the force applied during the milling operation. Also the low moisture of $14 \%$ obtained from platform was within the safe moisture content of 12 to $16 \%$ for milling of rice reported by [7], and [11] reported that drying temperature has significant effects on head rice yield and recommended temperatture between $35^{\circ} \mathrm{C}$ to $45^{\circ} \mathrm{C}$ for high head rice recovery. According to [11] to obtain a minimum amount of kernel breakages in Igbemo rice, paddy should be parboiled for 41.5 minutes and milled at $16 \%$ moisture content.

\section{Conclusions}

A steam heated platform dryer was successfully designed, fabricated and tested. From the test results obtained for the performance evaluation of the fabricated steam heated platform dryer, the following conclusions are made: the machine was able to effectively dry $335 \mathrm{~kg}$ of parboiled paddy rice from an initial moisture content of $30 \%$ (wb) to a final moisture content of $14 \%$ within the period of two hours. The machine was found useful in eliminating the limitations and drudgery associated with sun drying. A 
uniform drying rate was recorded with the use of the machine. A high head rice recovery of $90 \%$ was obtained when the paddy dried with the machine was milled using a milling machine. The rate of moisture removal was found to be $16 \mathrm{~kg} / \mathrm{hr}$. Generally, the machine was found to be very adaptable for commercial drying of Agricultural products such as melon, millet, yam chips etc. The dryer was also easy to maintain due to its simple design.

\section{References}

1. FAO (2012). Rice market monitor, Vol. XVI. Food and Agricultural Organization, Rome. Available: http//www.fao.org/docrep/017/aq144e/aq144e.pdf.

2. S. Mounir, and K. Allaf, "DIC-Assisted Hot Air Drying of Post-harvest Paddy Rice: Instant Controlled Pressure Drop (D.I.C.) in Food Processing," Fundamental to Industrial Applications, Food Engineering Series 2014. Springer, 2014, pp. 45-55.

3. S. M. Couto, "Modeling grain drying as discharge of an RC electrical circuit," Trans. ASAE 2002, 45: pp. 14451454.

4. E. K. Akpinar, "Determination of Suitable Thin Layer Drying Curve Model for Some Vegetables and Fruits," Journal of food engineering, vol. 73, pp. 75-84, 2006.

5. International Rice Research Institute, Paddy Drying, Postharvest Unit, CESD Version 2, October 2013 Available: http://www.knowledgebank.irri.org/images/docs/training-manual-paddy-drying.pdf.

6. M. G. Ibrahim, A. A. Shehu, S. M. Dauda and D. Ahmed, "Design, fabrication and testing of shea nut shelling machine," International Food Research Journal 23(Suppl): pp. S71 - S79, 2016.

7. M. N. Seyed, and M. E. Sayed, "Energy Use Efficiency of Different Drying Methods for Two Rough Rice Cultivars," Food Science and Technology, vol. 3, no. 2, pp. 23-28, 2015.

8. A. Gbabo, I. M. Gana, and M. S. Amoto, "Design, fabrication and testing of a millet thresher," Net Journal of Agricultural Science, vol. 1, no. 4, pp. 100-106, 2013.

9. A. Gbabo, L. Abdullahi, and A. M. Kuku, "Design, Fabrication and Testing of Improved Traditional Rice Parboiler dentification of common molecular subsequences," International Journal of Engineering and Technical Research, vol. 2, no. 9, pp. 331-338, 2014.

10.L. R. Wilhelm, A. S. Dwayne, and H. B. Geraid, "Drying and Dehydration," in Food \& Process Engineering Technology. American Society of Agricultural Engineers, 2004, pp. 259-284.

11.M. O. Adesoji and A. A. Abiola, "Conceptual Design of Column Dryer for Paddy Rice including Fabrication and Testing of Prototype," International Journal of Basic and Applied Science, vol. 2, no. 3, pp. 11-20, 2014. 